\title{
Widget Based Learning in Math and Physics Undergraduate Courses as Blended Learning Approach
}

\author{
By Francisco Javier Delgado-Cepeda ${ }^{*}$
}

\begin{abstract}
This work summarizes the didactic design and introductory outcomes in an educative program, involving six math and physics university courses for engineers, based on the use and construction of widgets. Widgets were generated under Project Oriented Learning and blended learning methodologies. In the program, widgets previously generated by teachers are firstly used by students to appropriate basic and middle concepts. After, students were requested to generate their own widgets to develop complex thinking skills, applying related concepts but involving alternative situations. Design was based on curriculum integration to build mathematical, technical and visual representations of the problems and concepts involved. Wolfram Alpha, Desmos and Mathtab widget developers were used to generate ad hoc activities in terms of their capabilities and course requirements. Post-test only results of students' value perceptions indicated positive attitudes towards the use of widgets. Differential gain in the general learning performance between experimental and control groups was less conclusive. Researcher observations of teachers' educative technology skills acquired are also reported.
\end{abstract}

Keywords: blended learning, higher education, mathematics, physics

\section{Introduction}

Nowadays, technology has a critical role in education. Departing from the adoption of computers in education several years ago, the current mobile accessibility to information and online applications has increased the inclusion of technology in this arena. Today, the support of technological resources is part of a planned teaching strategy. Thus, in the contemporary education trends, deeper distinctions about learning styles have introduced flexibility and adaptability in learning. As a result, complementarity between technology and traditional education has generated practices such as blended learning (Allen, Seaman, \& Garret, 2007; Bartolomé, 2004; Buzzeto-More \& Sweat-Guy, 2006), an educative approach emerged from technology to reach adequately the final recipients in a ubiquitous way. In the current days, mobile devices embody the convergence of many apps ready to enrich education: electronic book readers, annotation, creation, and composition tools, social networking communication, digital and editing tools, GPS, accelerometers, compasses, and extensible ports to connect sensors. All of them can be used creatively in the classrooms and labs.

The increasing demand of education has required accessible, cheaper and

${ }^{*}$ Full Professor, Monterrey Institute of Technology and Higher Education, Mexico. 
competitive online educative resources to reach educative goals in the best possible way. Normally, they are based on adaptive instructions assisted by technology (Johnson, Smith, Willis, Levine, \& Haywood, 2011). Such flexible and effective education becomes more disruptive than face-to-face education; which is normally based on abstraction of detailed content and is rarely based on experimentation. In this sense, meaningful learning (Ausbel, 1963) is based on knowledge closely related with the environment student. Under a meaningful learning strategy, new learning material should be based on a previous cognitive structure and a deliberate effort to relate higher-level knowledge with the daily reality, events or objects, generating an emotional connection with real applications. In this trend, a debate between meaningful learning versus a dense curricula (Gaer, 1998; Woessmann, 2001) is carried out in education.

In this philosophy, the maker movement (Dougherty, 2012) is closely related with meaningful learning. In nowadays, the use of simulators, dedicated sensors and automated software has generated a decreasing action directed to solve practical problems. Then, technology sometimes induces an autogenerated passivity in learning: students passively learn information from teachers and then reproduce it on notebooks and computers, but rarely in the real world (Shibley, 2014). Thus, students become information recipients rather than developers of applied knowledge. Project Oriented Learning (POL) (Algreenand \& Moesby, 2001) is an educative methodology based on Maker philosophy to develop the apprehension of knowledge as a result of prototypes, designs or software construction. This approach is an inheritance from technical disciplines.

A blended learning strategy has been growing in the last years as a useful practice to reinforce or complement some aspects of face-to-face instruction (DeNisco, 2014). But mobile technology is an ambivalent tool. There, only the most creative and engaging resources captivate to the users. Thus, teachers should prepare activities to fulfill learning processes and a ludic engagement in them. There are several approaches to a blended learning strategy (DreamBox Learning, 2013; Staker \& Horn, 2012), in terms of didactic orientation for the class, the amount of online contents, and the work being developed. Blended learning has been for the last years an amazing lab for teachers who are experimenting improvements in their classes supported by technology (Lothridge, Fox, \& Fynan, 2013). Particularly, blended learning has been used to develop and to train specific skills developed in the curricula (DeNisco, 2014), an important issue in higher education.

Together, education in Science, Technology and Math has been revalued as a requirement of global competitiveness. STEM education (Gonzalez \& Kuenzi, 2012) is an acronym of Science, Technology, Engineering and Mathematics. This movement began in Occident, but actually is spread in several regions of the world (Gonzalez \& Kuenzi, 2012). This initiative includes education at all levels and attends to the emergent necessities in the workforce market for the next years, trying to revert the current education data in the world. 
The aim of this paper is to propose a program based on the use and construction of widgets as a blended strategy for math and physics courses in the university. The proposal is based on a current project for the design of educative widgets. In the second section, the educative background and the blended scope are settled, together with the current research questions and objectives for this work. The third section deals with the contents coverage together with the technological design, tools and activities construction departing from a methodology of construction. There, the final didactic design and technological construction is sketched. After, the fourth section discusses the capitalization in terms of the teachers' experience, the student perception and some insight outcomes compiled on the basis of qualitative and quantitative aspects for the initial deployment. At the end, the conclusions about ongoing and future work are given.

\section{Background and Blended Learning Strategy}

Educative online tools have been growing exponentially in the last decade with the ubiquitous connectivity (Edublogs, 2013). It is time for teachers to be familiarized with online resources and meaningful applications to improve the learning quality and the engagement of students, particularly knowledge related with contextual constructions (Conole, 2008; Engelbrecht \& Harding, 2005). Among these technologies, apps to visualize concepts, letting interaction in addition, could serve for educative purposes. Widgets are apps designed to achieve specific tasks (Educastur, 2012). In particular, educational widgets focus on concrete knowledge development. They are constructed as specialized calculators or as interactive visualization tools around a technical problem or an abstract concept. iTec (2013), an initiative from the European Economic Community, has selected this trend as a key piece in learning.

In terms of blended learning, widgets-based learning is located between the face-to-face driver model and the online lab model (DreamBox Learning, 2013). In other dimension, widgets are based on the creation of personal environments of learning by letting each student experiment and to try the own learning registers (Gkatzidou \& Pearson, 2011; Person, Gkatzidou, \& Green, 2011). In fact, each widget covers a great extent in learning by introducing lots of variations, boosting the creativity and asking the internal questions of the user on demand. These elements let the teacher complement the class with directed activities that are oriented to experimentation in the use of well constructed activities. Otherwise, they are directed to innovation, creativity and skill reinforcement when a user constructs widgets for others. For the teacher, widgets let him share knowledge and experiences which are not possible to include in the face to face instruction time (Young, 2008), in particular with the wide curiositythat his class requires. Marino (cited by Guess, 2008), has stated that widgets can close the distance with abstract concepts and situations in just a click. They encourage the curiosity and in 
nowadays they are really easy to construct.

The Monterrey Institute of Technology and Higher Education (Instituto Tecnológico y de Estudios Superiores de Monterrey, ITESM) is a university system continuously evolving its educative methodology in the last 20 years. In particular, for the engineering disciplines, Problem Based Learning (PBL) (Polanco, Calderon, \& Delgado, 2001), Project Oriented Learning (POL) (ITESM, 2007), curriculum integration (Delgado, 1999) and use of educative technology (Delgado, 2011) have been strategies to improve the effectiveness, sense and quality of learning. The Physics and Mathematics Department has emphasized curriculum integration and the use of technology in the classroom as a builder of affective relationships between reality and abstract concepts (Delgado, 1999; Polanco, Calderon, \& Delgado, 2001). The transversal use of professional software as Mathematica ${ }^{1}$, a software to do analytical and numeric mathematics, has been used in associated courses to introduce curriculum integration by solving applied problems in context (Delgado, 2011), thus developing the upper Bloom's taxonomy levels (Anderson \& Krathwohl, 2001). While POL, as a didactic strategy, has been used as link between the Math and Physics curricula (ITESM, 2007).

Johnson et al. (2011) established that mobile devices are the main tool to reach the Internet, generating ubiquitous connectivity and a large-scale development of applications accompanying all time to the users. Internet has too become the main unofficial source of learning. Since 2011, a program to boost mobile learning has been developed in Tecnológico de Monterrey (Delgado, 2014), based on academic research, sharing, training and assessment to improve mobile education. This effort developed digital competences for mobile learning in all discipline teachers, without previous knowledge. Today, the program generates initiatives and educative trends pursuing an easy implementation by the faculty. Then, tools involved are required to be accessible, easy and useful for each discipline and learning activity, to scaffold the learning process as a premise.

In terms of the math and physics curricula, the contents are ambitious and not always based on applications or visualizations. Together, the use of Mathematica requires a sustained effort for teachers and students, mainly due to its syntax. Instead, a course based on the use of widgets, properly generated by teachers, could generate a better apprehension of knowledge. While student construction of widgets through concrete projects; could boost students' analysis and creation from Bloom's taxonomy (Delgado, 2013a), concrete projects work as an affective link for meaningful learning. Each widget constructed by the teachers fulfills specific educative goals (Delgado, 2013b). A complementary practice to construct widgets by the students could develop higher-level comprehension through applied problems. In both schemes, use and construction, a better comprehension is achieved when each student uses widgets and then, new widgets are proposed, designed and constructed.

This practice is expected to promote a better domain of the basic concepts.

\footnotetext{
${ }^{1}$ http://www.wolfram.com
} 
Courses involved belong to the first four semesters of engineering programs: differential and integral calculus, several variables calculus, differential equations, probability and statistics, mechanics, fluids, heat and waves, electricity and magnetism. The final potential number of students involved in the program is estimated in 1,200 students. A detailed discussion in terms of courses and curricular integration is included in Delgado (2013a). The strategy includes these activities under a blended learning environment. Thus, lectures, solving exercises, use of widgets (widget based learning), and widgets construction (POL) are combined as global strategy (Figure 1a).

The main curricular relations are shown in Figure $1 \mathrm{~b}$, including representative topics and courses in both disciplines. As it was discussed in Delgado, Santiago, \& Quezada (2015), the requirements in each course are different: visualization for calculus and probability courses, algebraic skills for differential equations and a blend between visualization, specialized algebraic and arithmetic calculations for physics. Thus, a unique widget developer tool hardly completely covers this spectrum, so three different widget developers were finally selected: Wolfram Alpha, Mathtab and Desmos.

Figure 1. a. Widgets Based Learning Embed as Strategy in the Course, b. Main Curriculum Integration Links in Widgets Design

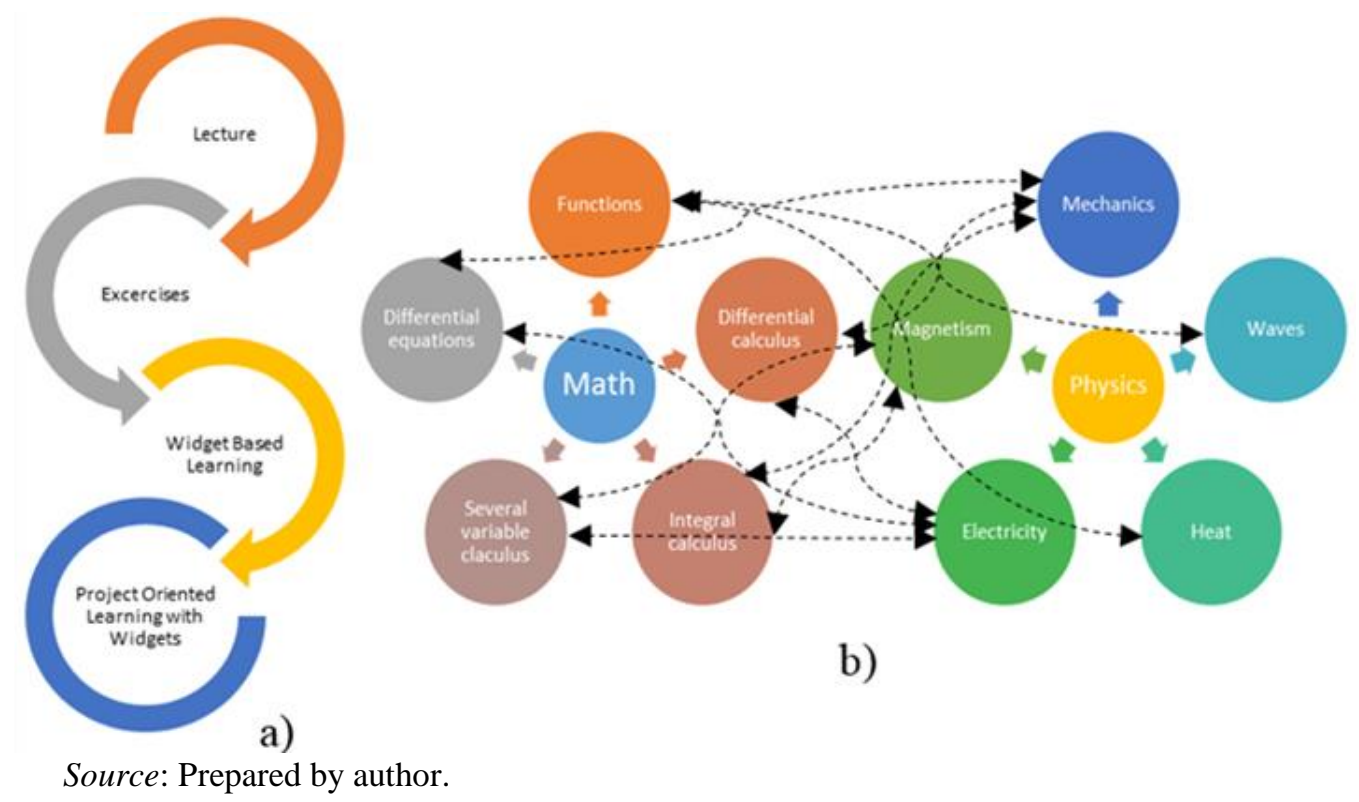




\section{Widget Design Methodology and Research Objectives}

The development of the educative program presented was based on a mobile site $^{2}$ constructed on Weebly ${ }^{3}$ (Delgado, 2013a; Delgado \& Santiago, 2014) integrating the courses involved, their widget based activities (widget, didactic guide and widget proposal for the construction activity by the students) and a tutorial. The site includes forms designed with Jotform $^{4}$ to retrieve information and images. They are integrated with Googledrive as a repository. These interactions and tools are thoroughly described in Delgado, Santiago \& Quezada (2015). Widget activities are divided among the six physics and engineering courses so that each course contains between four and six activities. Each activity contains: the widget, the didactic guide or questionnaire, the information retrieval form and the related activity to construct widgets (Delgado \& Santiago, 2014).

\section{Research Questions and Research Objectives}

The research questions that arise in the current work examine the impact of widget use and development on student learning and faculty development: (a) what are the students' perceptions about using widgets in terms of skill development, intellectual challenge and meaningful learning? (b) how does widget development affect learning performance of course content, and (c) how does widget program have improved the faculty's teaching skills? Thus, the objectives of the current research are: (a) to obtain quantitative data about the students' perception of the program in aspects as skill development, challenge and meaningful learning activities; (b) to get a quantitative insight evidence on the general learning performance in the course contents; and (c) to report the teaching skill development for the faculty due to this project.

\section{Methodology}

The methodology is centered on the widgets activities design to get quantitative evidence on the last issues. The study being reported is comprised during one semester from August 2014 to December 2014, including the faculty workshop. Student participants were drawn from the differential equations, numerical methods and physics I courses. There were two sections for each course with around 25 students in each one for a total of 143 student participants. All of them were engineering students, the target of this project. Courses belong to the fourth, third and first semesters of the engineering programs respectively, in the freshman and sophomore sections. All sections were taught by the leader group of teachers in the widgets program, all of them Full professors with more than 25 years of teaching experience. Each professor taught two sections of one course. The researcher conducted weekly workshops

\footnotetext{
${ }^{2}$ http://itesmcem-fmwidgets.weebly.com

${ }^{3}$ http://www.weebly.com

${ }^{4} \mathrm{http}: / / \mathrm{www}$.jotform.com
} 
to disseminate some of the experiences in the project related with the learning technology use. Faculty workshops were mainly attended by the three course professors with some punctual interventions of other members of the physics and math faculty. The researcher documented and wrote weekly detailed observations of each workshop that included participant attendance, individual performance and the individual fulfillment of specific products derived there. These observations were analyzed for emergent themes.

Students' perceptions about widget use and widget development were measured using a continuous scale survey applied once at the end of the semester. The researchers defined the following dimensions in the survey: (a) the meaningful learning value for the widgets' use activities, (b) the meaningful learning value for the widget construction activities, (c) the affectivity on the skill development of the program, (d) the strength of the curriculum integration on the widget activities (use and construction), (e) the relative value for the visualization approach in the widgets program (versus the calculator approach in it), (f) the learning value (versus no meaningful learning or waste of time perception), (g) the engaging activity perception (versus boring activity perception), and (h) the activity challenge perception (versus no difficulty). Students rated these dimensions on a $0-1$ continuous scale where 0 and 1 represent respectively $0 \%$ and $100 \%$ for percentages (questions a-d), and 0 and 1 for dichotomy (questions e-g), respectively. This survey was administered in all six courses once after students completed all widget activities. In spite that outcomes are not expected to be representative for the whole population in the engineering courses, any calibration for this survey was conducted, due in addition to the similarity among the population for each course, in case that the semester program maturity could be a variation factor. Gender was not considered as a variation factor due to performance for this variable is non-sensitive for the engineering programs in the university.

Learning performance in the course was measured through an analysis of students' comparative performance in the widget activities and the whole course evaluation related to previous students who were not exposed to the widgets program. Analytics between the classes involved and other old classes for the same courses, used as reference, were based on the following dimensions: (a) widget construction completed, (b) average grade in widget use activity, (c) average grade in widget construction activity, (d) ratio between grade in the course final grade and in the average widgets activities for each student, (e) dispersion of the last indicator (standard deviation), (f) relative differential gain between introductory and final exam grades in the course (with eight years of following in the Physics and Math department), and (g) and the dispersion of the last indicator (standard deviation). There are no control groups in the current study, instead, final comparison of these average gains in each course is then compared with the corresponding eight years' historical statistics for each professor teaching specific courses.

For the faculty, the single participation statistical data were analyzed and a genealogical map of relevant teaching technology through the several 
initiatives in mobile learning training for teachers is presented and discussed. In the following part of the section, the widgets program strategy is depicted to arrive in the next section on the evaluation proposed in the research objectives.

\section{Site Design}

The first part of each activity in the physics and mathematics Widgets site (Delgado, 2013b) embeds a widget constructed by the faculty, fulfilling two educative guidelines: (a) it is oriented to identify relevant variables associated with a math or physics concept, and (b) it lets us comprehend how this concept is related with a real situation. A questionnaire is included with each widget to generate an oriented and challenging interaction. Together, there is a delivery form to report the results and to get a receipt of acknowledgment (Delgado \& Santiago, 2014). The second part is the complementary practice for widget construction to develop high-level comprehension in an applied problem. Commonly, it integrates the concept on which the proposal is centered together with other concepts in related courses.

The courses involved in the program (transversal and sequential) required an initial construction of widgets based on some critical topics. The widgets let an online interactivity by exploring a concept through an interactive visualization attempting to develop complex thinking in a complementary activity when students construct their own widgets. Thus, widgets are embed in a didactic purpose to discover several aspects of the theory (Part 1) and then, to use more complex knowledge to design new widgets for specific concepts (Part 2). The main lines of project were depicted by Delgado (2013a). This construction philosophy could serve as a guide to other teachers adopting these ideas in other courses or disciplines.

\section{Widgets Developers Related with the Project Purposes}

In the selection of widget developers, alternative tools were considered to fulfill specific necessities of each course. As a result, Wolfram Alpha, Desmos $^{6}$ and Mathtab $^{7}$ were included in addition. Widgets for differential equations, electricity, magnetism, and several variables calculus courses were mainly achievable with Wolfram Alpha; Desmos and Mathtab were used in the further courses, being the second most adequate for physics courses. The following subsections briefly depict each widget developer, to discuss their use in the project.

Wolfram Alpha. Wolfram Alpha is a free syntax computational knowledge engine closely related with Mathematica, but simpler and with automated outputs. This has an associated widget developer whose products work as user interfaces to manipulate selected variables in the syntax. They can

\footnotetext{
${ }^{5}$ http://m.wolframalpha.com

${ }^{6} \mathrm{http}: / / \mathrm{www}$. desmos.com

${ }^{7}$ http://mathtab.com
} 
be embedded in websites.

Because Wolfram Alpha interprets queries and then obtains processed information (inclusively in a mathematical or statistical way), it can be oriented to show the analysis of the solutions for mathematical problems. The initial inspiration to develop the widget program due to its similarity with Mathematica came from Wolfram Alpha widgets. Later, other tools were necessary to reach more specific goals. Figure 2a shows screenshots for the widget activity in the electricity and magnetism course generated with this tool. In it, positions and strength charges should be captured to obtain an equipotential map. A widget is accompanied with a questionnaire to interact and a delivery form to report the outcomes sending individual student reports to Googledrive (Figure 2b). Nevertheless the complex mathematical outcomes can be reached. The outputs are limitedly in control of the design teacher who just selects them from a predefined set. Normally, this issue restricts the possibilities to create some widgets, in particular for elaborated issues as those for kinematics or dynamics. Animations are rarely obtained.

Figure 2. a. Wolfram Alpha Widget to Obtain Equipotential Curves for PointLike Charges, b. Questionnaire and Interaction Form Linked to Googledrive

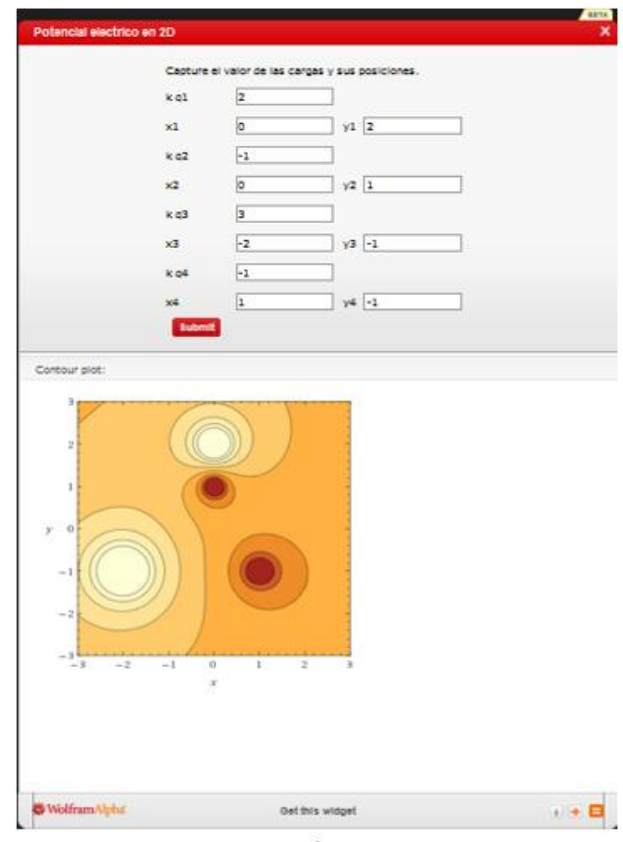

a)

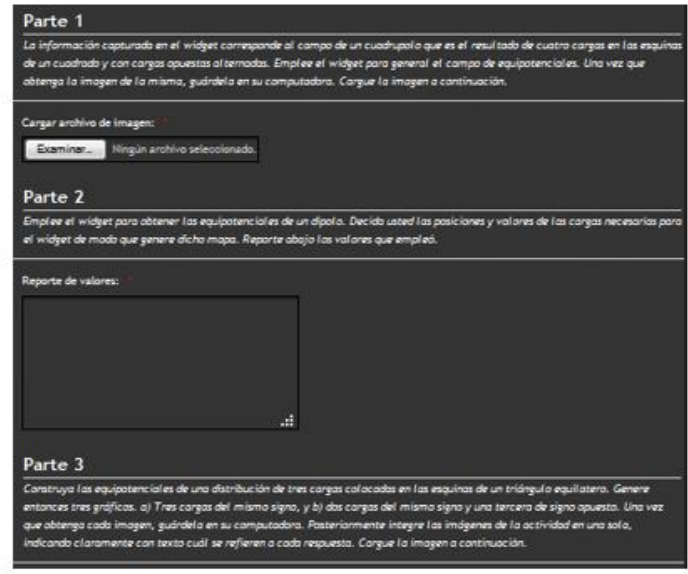

b)

Source: Prepared by author.

Desmos. Desmos is a tool oriented to visualize mathematical concepts and objects in an attractive graphical and interactive way creating geometric visualization departing from algebraic expressions. Parameters can be introduced to generate automatic interactivity and movement. Nevertheless their narrow diversity oriented to manipulate only this kind of objects, is valuable in calculus, differential equations, probability, and statistics courses to 
show geometrical relations with calculus.

Figure 3a illustrates a widget showing the concept of the curvature circle. The widget interactively changes the parametric curve and the point in which circle is tangent. All calculations are analytical. Nevertheless the aesthetics and the wide spectrum to visualize mathematical concepts in an automated way, it is not always easy to represent more complex problems than those closely related with mathematical objects. Despite, Desmos widgets are excellent elements to show calculus in movement. The didactic guide (Figure $3 b$ ) can include many exercises including several variations to probe several aspects of algebraic calculations.

Figure 3. a. Desmos Widget Showing the Circle of Curvature for a Parametric Curve, b. Didactic Guide and Interaction Form Linked to Googledrive

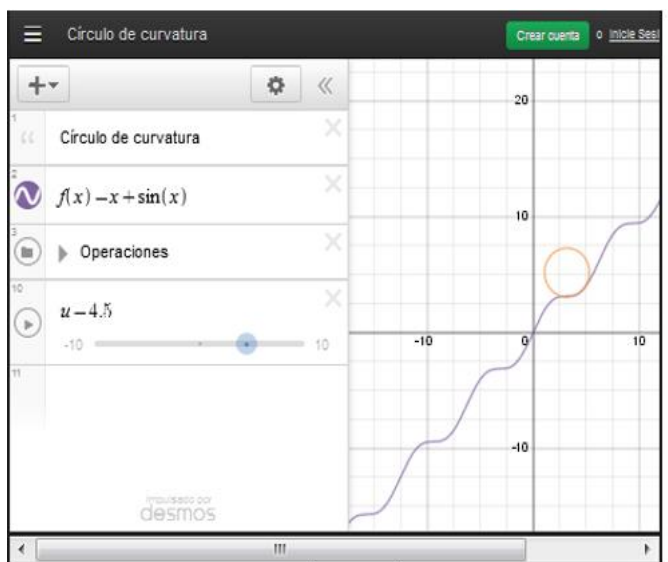

a)

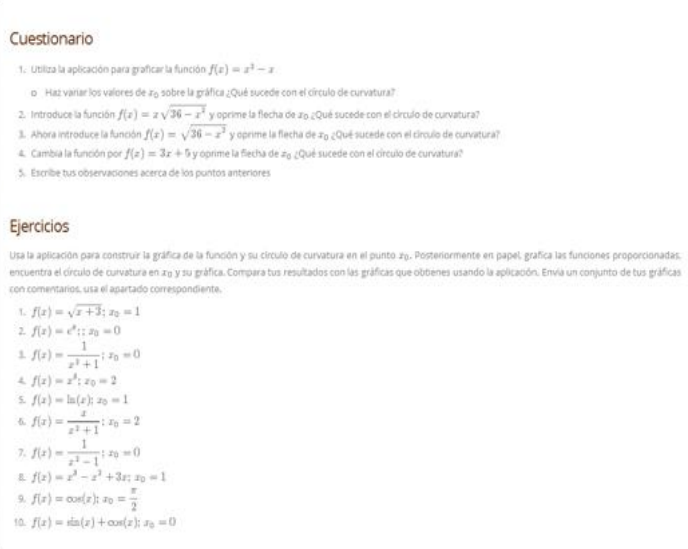

b)

Source: Adapted from Delgado et al., 2015.

Mathtab. Mathtab is a tool oriented to generate specialized calculators and $2 \mathrm{D}$ animations. It includes a user interface, worksheets and classical programming when it is necessary. Mathtab becomes ideal for physics widgets, solving quantitatively the behavior of complex systems with multiple outputs. Mathtab widgets are used with a two folded intention: a. to review direct exercises by introducing the precise input values to obtain the output ones, or b. to review complex problems where students first should develop the whole calculations departing from the output values to obtain the correct input ones. 
Figure 4. a. Mathtab Widget to Analyze Non Central Collisions in Two Dimensions, b. Questionnaire and Interaction Form Linked to Googledrive

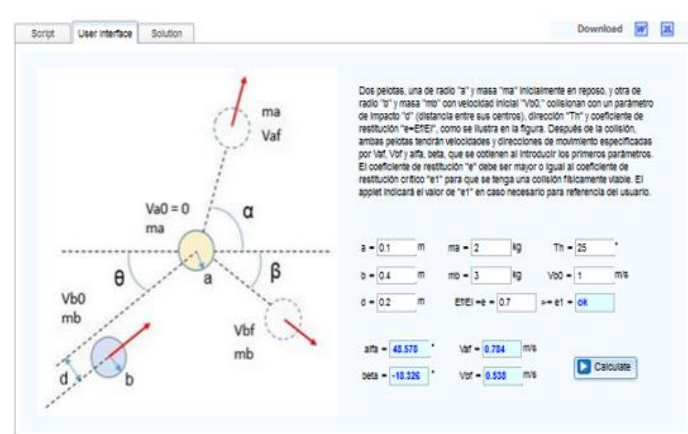

a)

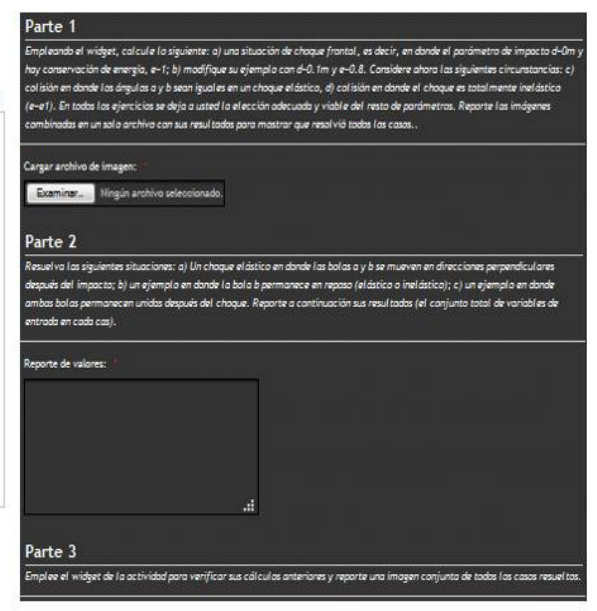

b)

Source: Adapted from Delgado et al., 2015.

Nevertheless Mathtab has a limited graphic interface to show objects and graphs in two dimensions, its capability in programming allows really complex situations to be included. Figure 4a shows a dedicated widget to relate the group of variables in a non-central collision in two dimensions. Mathtab is considered to construct specialized calculators to set a group of input values generating another group of output values. Mathtab lets us define user functions and procedures by programming, so numerical complex capabilities are possible in principle. Didactic guides can be constructed to obtain and to report different solutions in an applied multivariable problem. These calculators could be used in a direct way to simply review the result of a straight problem or to review the concordance of variables in a specific situation (when only a part of input and output variables are known). As before, retrieval information forms help to report results or images (Figure 4b).

\section{Didactic Site and Structure}

The widgets project was centered in the development of widget activities for all courses appointed. They were located and ordered by course in the mobile widgets program site (Delgado, 2013b). This site contains: (a) a tutorial, (b) a FAQ blog, and c) activities of analysis by a course and by widget built by the faculty. They are based on strategic and representative topics selected for this program. Each widget includes a didactic guide of interaction, which is sometimes a questionnaire or an exercise series requiring the use of the widget. Questions were designed to generate interactivity. Together, this is an online report form embed in the same activity page. Each activity in this site includes supplementary activities to develop one new additional widget by the students. This site and their sections were depicted in Delgado; (2013a). 
Curricular design of math widgets. Calculus courses are the most representative in university math, having several related concepts and weakness in their abstraction. Widgets could contribute to both: visualization and algebraic experimentation if they are based on experiential learning styles (Kolb, 1984). In addition, visualization and in particular continuity are underlying issues on which learning should be focused. The last concepts are applied in a differential equations course. Thus, a net of widget activities were created to give a whole picture of calculus. Figure 5 shows a simplified scheme containing the main themes in the calculus courses, their curricular associations and the widget developer were used in each specific activity. The associated widget construction could be addressed on a different developer depending on the aspect being realized. In that design, not only the topics were selected, but the best widget developer to fit its attributes with the activity purposes. Thus, Wolfram Alpha widgets let to create automated math outputs to show elaborated graphics or algebraic calculations despite its limited animation possibilities. Instead, Desmos widgets were able to show delicate and attractive animations in an interactive way. Both developers were used in several activities in agreement with the learning focus.

Figure 5. Schematic Curricular Design for the Activities in the Main Math Courses, Showing Deliberate Curricular Relationships with Dashed Lines

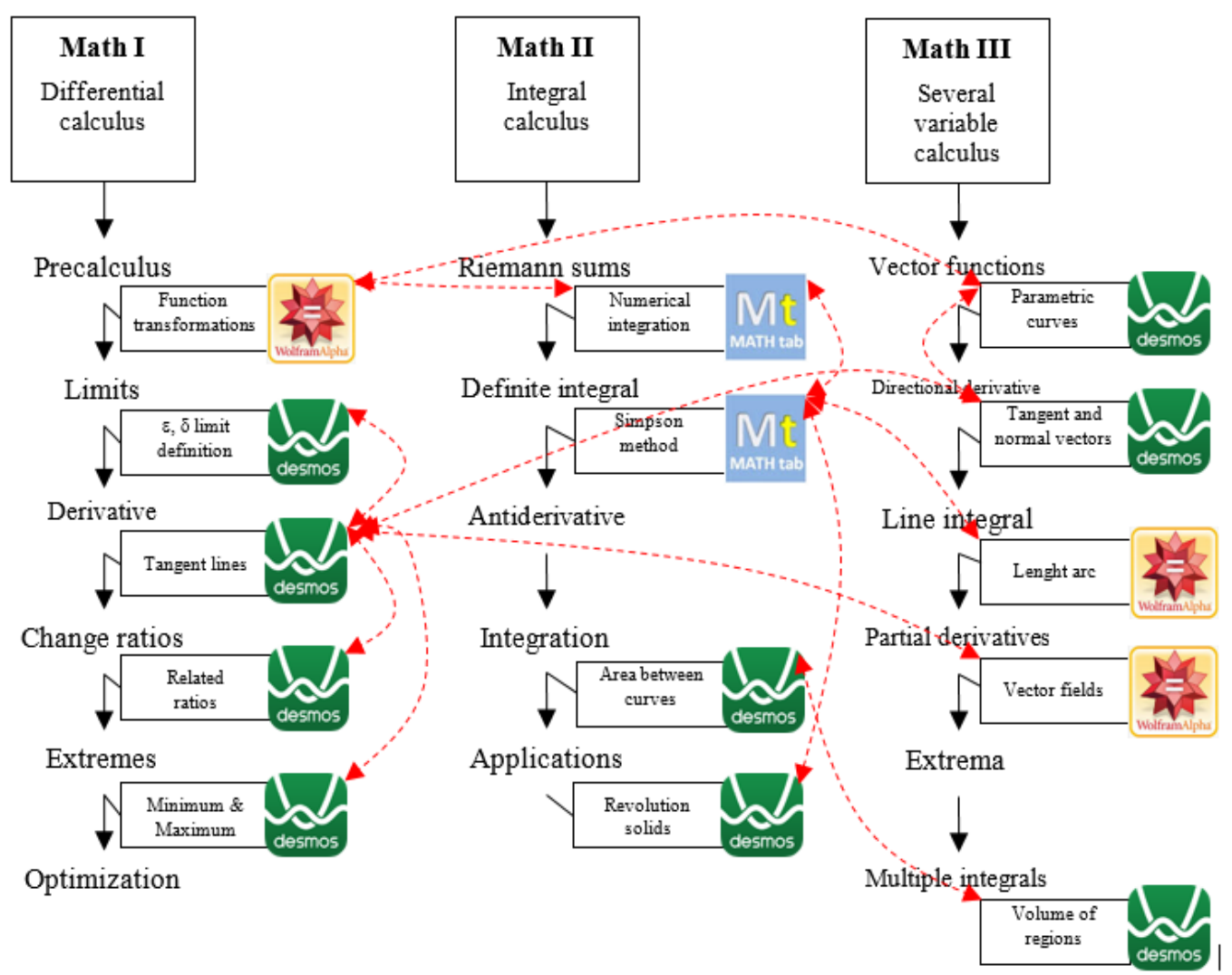

Source: Prepared by author. 
Curricular design of physics widgets. Physics scenarios for mechanics, waves, fluids and heat are more quotidian, so visualization is superseded by dominion of laws underlying and the complexity of associated calculations. Then, a specialized calculator is more practical than an animated simulator. In contrast, electricity and magnetism concepts require the visualization of abstract elements and their mathematical relations involved. Figure 6 shows the simplified curricular design for the widgets net constructed for Physics courses and their curricular relationships. In those terms, Mathtab was an excellent developer to include widgets working as specialized calculators for physics I and II, while Wolfram Alpha was reserved for the electricity and magnetism course because vector fields, contour curves and other related math concepts were deeply involved and they should be presented as visualizations.

\section{Outstanding Results in an Introductory Research and Analysis}

The physics and mathematics widgets program has generated notable outcomes during an introductory inquiry through an initial controlled and limited deployment. In this section, we describe briefly the most important ones. This study is based on the experience of three major teachers working as leaders of the project and spreading it to several colleagues in the math and physics faculty, all of them Instructor, Associate and Full-time Professors. The groups whose outcomes are reported here were conducted by the three leaders and two more Associate Professors involving Physics I, Math I, II and III, as well as Numerical Methods courses.

Figure 6. Schematic Curricular Design for the Activities for the Physics Courses, Showing Deliberate Curricular Relationships with Dashed Lines

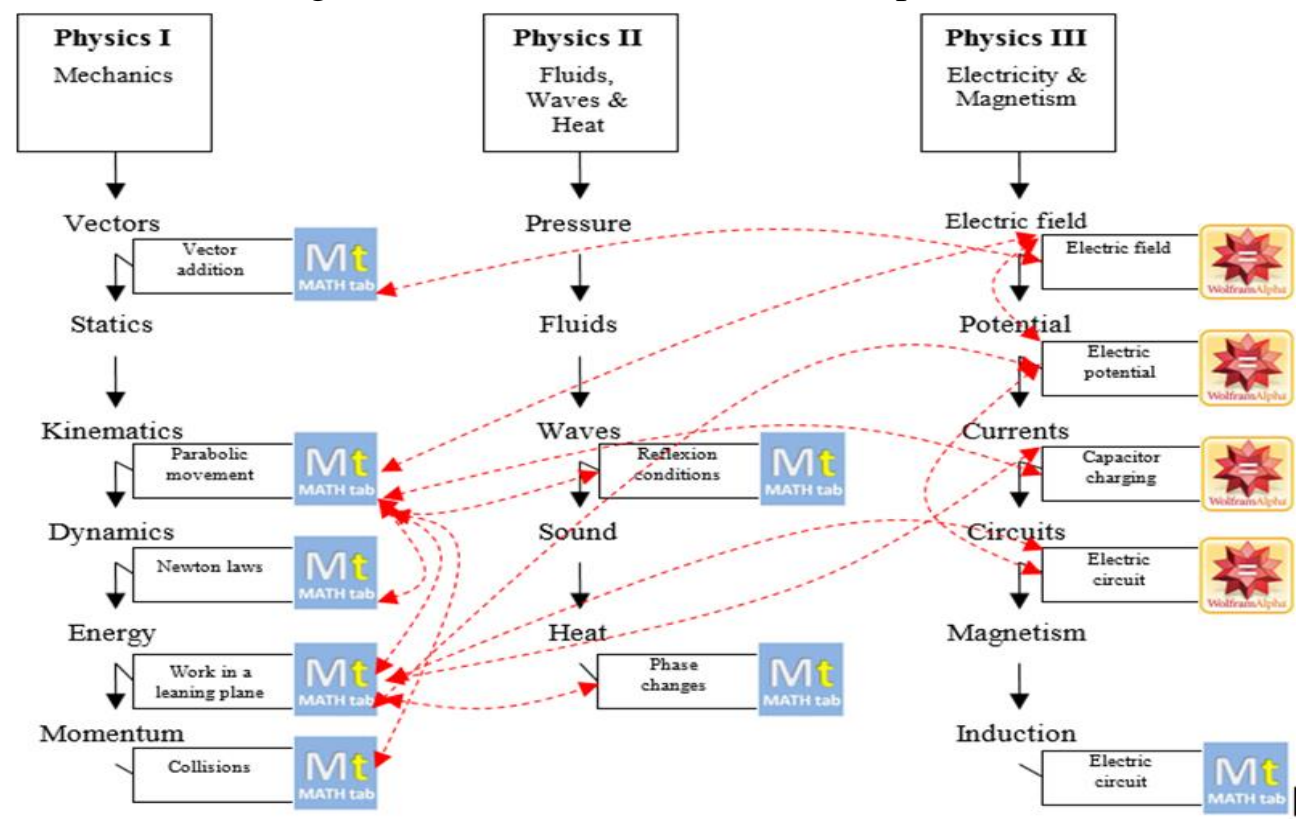

Source: Prepared by author. 


\section{Outcomes Related with the Impact on Student Learning}

A more detailed report of findings in the student learning impact was reported in Delgado, Santiago, \& Quezada (2015) as part of an introductory deployment. Based on a one year research on six pilot groups and using several widget activities constructed, a perception evaluation was also applied. In addition, a quantitative exploration of the possible impact in learning compared the historic results in the course with the current courses using widgets. Inquiry was applied on three different courses using and constructing widgets: differential equations course, numerical methods and physics. Table 1 depicts the distribution of the population being considered (note it is not considered in this study as a sample of the whole engineering student population, experimental conditions clearly does not let consider it as a sample).

Students' value perception. The outcomes are reported clockwise in the Figure $7 \mathrm{a}$ based on the perception averages in each dimension (\%) depicted in the Methodology section, thus as their corresponding standard deviations (s). All results are shown in a 0 to 1 scale $(0-100 \%$ for percentages in questions a$\mathrm{d}$; and 0-1 scale for dichotomy questions, e-g).

Table 1. Outcomes of Widgets Program's Perception Student Survey

\begin{tabular}{|c|c|c|c|c|c|c|c|c|c|c|c|}
\hline \multirow[b]{2}{*}{ Course } & \multirow{2}{*}{ 苞 } & \multirow{2}{*}{ 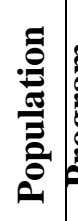 } & \multirow{2}{*}{ 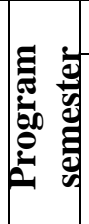 } & \multicolumn{8}{|c|}{ Average outcomes by section } \\
\hline & & & & a) & b) & c) & d) & e) & f) & g) & h) \\
\hline \multirow{2}{*}{ Physics I } & 1 & 23 & 1 & 0.54 & 0.91 & 0.65 & 0.54 & 0.52 & 0.72 & 0.79 & 0.52 \\
\hline & 2 & 26 & 1 & 0.64 & 0.73 & 0.72 & 0.63 & 0.64 & 0.69 & 0.73 & 0.55 \\
\hline \multirow{2}{*}{ Differential equations } & 1 & 24 & 3 & 0.62 & 0.85 & 0.81 & 0.70 & 0.71 & 0.79 & 0.85 & 0.67 \\
\hline & 2 & 21 & 3 & 0.59 & 0.84 & 0.69 & 0.68 & 0.65 & 0.72 & 0.90 & 0.63 \\
\hline \multirow{2}{*}{ Numerical methods } & 1 & 24 & 4 & 0.65 & 0.77 & 0.73 & 0.67 & 0.68 & 0.88 & 0.83 & 0.72 \\
\hline & 2 & 25 & 4 & 0.67 & 0.89 & 0.71 & 0.62 & 0.58 & 0.93 & 0.84 & 0.80 \\
\hline Average & - & 24 & - & 0.62 & 0.83 & 0.72 & 0.64 & 0.63 & 0.79 & 0.82 & 0.65 \\
\hline Std. dev.(s) & - & 1.7 & - & 0.49 & 0.38 & 0.45 & 0.48 & 0.48 & 0.41 & 0.38 & 0.48 \\
\hline
\end{tabular}


Figure 7. a. Perception Dimensions of Students around Several Aspects of Widget Activities (percentage in 0-1 scale \%, and standard deviation S), and b. Key Analytics Related with the Impact in Learning

Student perception

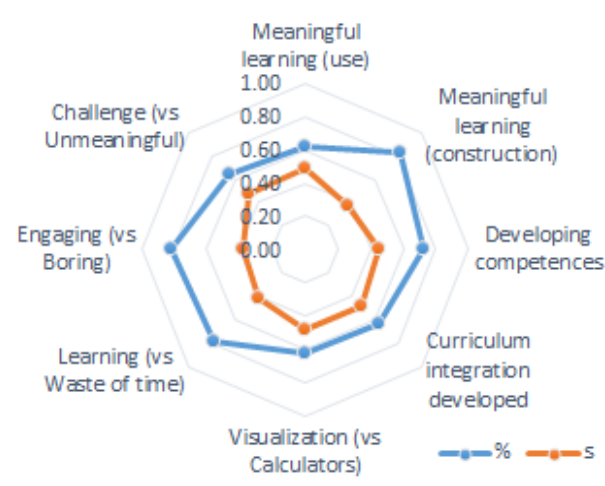

a)

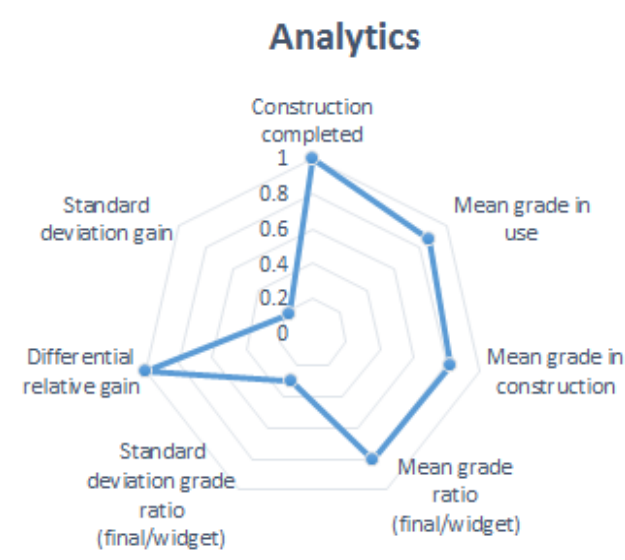

b)

The results show that perceptions about widgets construction, the degree to which the activity was engaging, and the learning value were mainly consistent among the students. While the worst aspects evaluated were the value of widget use, the relative value for the visualization approach, the strength of the curriculum integration, and the activity challenge. Nevertheless all averages are evaluated over than 0.6. Even so, aspects such as the relative value for the visualization approach in the widgets program and the meaningful learning in widgets' use activities exhibit large dispersion.

Impact on general learning performance. Detailed results are shown by course and section in the Table 2 and clockwise summarized in Figure 7b. As before, a 0-1 scale has been used. Results in a, b and $\mathrm{c}$ show that these activities are well completed and graded with satisfactory notes in average, so they appear as achievable activities for the most of the students. In addition, they appear consistent with the whole final evaluation, suggesting that these activities are neither extremely complex, neither trivial. Note that dispersions in $\mathrm{d}$ and $\mathrm{f}$ are low, but relatively consistent through the students. Note for the Physics I course, $\mathrm{f}$ is lower and more disperse.

For indicator $\mathrm{f}$, gain is defined as the difference between both exams depicted (the introductory one is an initial evaluation applied to all students in the first class week with eight years of following-up; the final is the end-course exam evaluating the overall content). Then, the differential gain is calculated as the difference of average gains between the current widget classes (Gain) with respect to the historic classes (Hist. gain) for the same courses (clearly without widget program running there). The relative gain is then calculated as the ratio between the differential gain and the historic gain. Surprisingly, the average gain became double in the widget groups, so the relative gain was 0.99 in the 
current scale. In fact, the historic gain is in average $\mu=4 \%$ with $\sigma=2.1 \%$. For groups in the widgets program it gave $\mu=8 \%$ with $\sigma=3.2 \%$. Despite the sample for this research is not meaningful to extend these results on the general population, it suggest a possible improvement in the general learning performance in the courses where the widgets program was applied, but more extent analysis should be developed in the future with large samples and considering other teachers than the project leaders.

Table 2. Outcomes for the Learning Performance Analysis

\begin{tabular}{|c|c|c|c|c|c|c|c|c|c|c|}
\hline \multirow[b]{2}{*}{ Course } & \multirow{2}{*}{ 氖 } & \multicolumn{8}{|c|}{ Average Outcomes by Section } & \multirow[b]{2}{*}{ g) } \\
\hline & & a) & b) & c) & d) & e) & כ] & 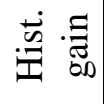 & f) & \\
\hline \multirow{2}{*}{ Physics I } & 1 & 1.00 & 0.80 & 0.74 & 0.72 & 0.41 & 0.60 & 0.32 & 0.87 & 0.12 \\
\hline & 2 & 1.00 & 0.87 & 0.79 & 0.75 & 0.34 & 0.53 & 0.32 & 0.67 & 0.30 \\
\hline \multirow{2}{*}{ Differential equations } & 1 & 1.00 & 0.83 & 0.86 & 0.83 & 0.24 & 0.84 & 0.38 & 1.21 & 0.12 \\
\hline & 2 & 1.00 & 0.89 & 0.81 & 0.77 & 0.23 & 0.81 & 0.38 & 1.13 & 0.13 \\
\hline \multirow{2}{*}{ Numerical methods } & 1 & 1.00 & 0.93 & 0.90 & 0.85 & 0.28 & 0.91 & 0.43 & 1.11 & 0.15 \\
\hline & 2 & 1.00 & 0.90 & 0.82 & 0.87 & 0.29 & 0.88 & 0.43 & 1.05 & 0.13 \\
\hline Average & - & 1.00 & 0.87 & 0.82 & 0.80 & 0.30 & 0.76 & 0.38 & 1.00 & 0.17 \\
\hline Std. Deviation & - & 0.00 & $\mid 0.05$ & 0.06 & 0.06 & 0.07 & 0.16 & 0.05 & 0.20 & 0.06 \\
\hline
\end{tabular}

Outcomes associated with development on teachers' technology skills. Mobile revolution has required that teachers should be involved with technological tools to create new educative resources and with meaningful applications to potentially improve or wide the learning quality. It requires adequate training and a change of mind to be supported by technology. Boosted by an institutional initiative to develop mobile learning, several projects were transversely promoted. Widgets Project was one of those. As a result, in addition to some courses directly developed in the institutional effort, a local faculty seminar on some mobile technologies was conducted, mainly due to the widgets project (Delgado, 2013a), the introductory workshop on widgets became a rich training experience. It was developed as a weekly seminar during one semester. Twenty-two math and physics teachers participated in training on educative mobile technologies. It became centered on different tools and activities in which teachers could be aided by technology inspired in the widgets experience: Mathics, Simpy, Math Studio, Geogebra, Wolfram Alpha, Mathtab, Desmos, Siminsights, Google-Classroom, Nearpod, i-books Author, e-Page, ExeLearning, Mathematica CDF's, Google-Forms, Jotform, Flubaroo and EducaPlay. A summarized genealogy about the tools learnt by the math and physics faculty is presented in Figure 8. It shows as this single effort has deeply boosted an exponential knowledge in those trends, crystallizing other related projects by using and combining these technologies: Online Calculus lab, m.physlab (a physics challenge lab) and several personal mobile courses (under blended learning approaches) as a teachers' initiative. 
Despite the last results, full time faculty were mainly involved with technological teaching developments $(100 \%)$, while partial time faculty were still poorly involved in these new and educative projects (less than 10\%).

Figure 8. Chained Advancement in Teachers' Mobile Learning Technologies Departing of Institutional Mobile Learning Initiative

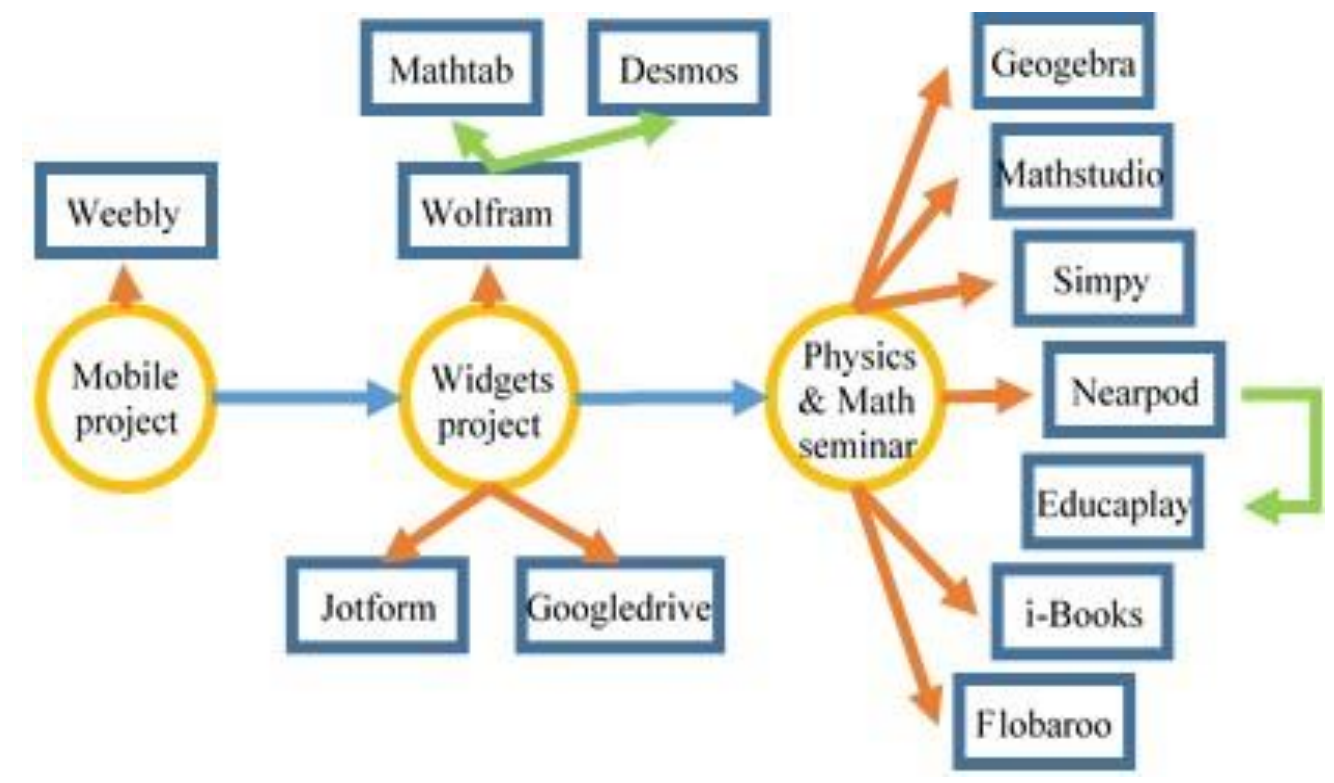

Source: Prepared by author.

Boost of derived educative projects. The development of widget program extended the teachers' skills and dominion in technology in terms of tools managed at the end by the faculty. This autonomy generated two new technology projects arisen from the widget program. The first is the Calculus lab (Santiago and Quezada, 2014), a creative experience of didactic design for 21 themes covering differential, integral and vector calculus, all of them based on Desmos widgets. Project is being conducted by four professors, under the directive from one leader in the widgets program. The second is m.Physlab, a mobile physics lab proposing 12 challenge real experiments in the lab physics with support on a mobile site including video tutorials for each experiment, initial and final automated evaluation of the theory involved, online developer of the experimental report, and embed specialized calculators of experimental techniques based on Mathtab. Five professors integrate this project under the directive from another widgets program leader. The technology being used in both projects was mainly introduced by the widgets program and sparkled in the weekly workshop. These initiatives shown the dissemination of widget program into alternative projects using similar technologies. 


\section{Conclusions and Future Development}

Education cannot be isolated from the daily scenario where mobile technology is present in almost each aspect of our life. This experience includes many tools able to generate educative resources easily available to teachers. Issues related with quality and depth of education should be addressed by new and old generations of teachers together. Although technology could be a creative tool to boost education by engaging to students, its limitations should not trivialize the knowledge, instead they should potentially improve the students' comprehension.

The widget program is an arena where students and educators have still much more to explore. Each student can spend time reflecting how to construct and use each widget by learning the underlying concepts. While for faculty, it can help to develop curriculum integration and reinforce different course concepts into concrete and real applications. Together, for teachers, it has been an initial introduction to learning mobile technologies. In the road, several tools letting technology integration, embedding, submitting, stocking up and gathering analytics open a creative world to be combined and assembled. Here, Wolfram Alpha, Desmos, Mathtab, Weebly, Jotform and Googledrive construct easily a more complex product with deeper educative goals. In the current program, widgets appear as a valuable learning activity based on visualization, exploring and tutoring. As a clear result in this introductory insight, widget construction appears to be a valuable and engaging activity that enhances learning, at least compared with the use of widgets, which is only mildly well evaluated. This knowledge, for teachers, normally boosts other ideas about alternative educative projects.

Definitively, computer technology is exponentially growing and spreading. In parallel, it is specializing and adapting to different teaching and learning styles. Continuous search of technological resources for the development of educative materials by teachers should be adopted as a modern educator value (Laurillard, 2002). A future work for this program will be based on to extend it until the greatest possible group of faculty, at least with other associated initiatives. Additionally, widget program should include a more extensive evaluation of educative outcomes by collecting and analyzing the results and the work of students in a follow-up study based on a more robust model to evaluate complex thinking acquisition as suggested by the preliminary outcomes presented here. Despite, in the current experience, widget project has been an example of new technological developments being carried out completely by teachers as a coordinated group, to learn, design and construct educative resources, with not just a modest technological assessment but with a rich teacher's sharing and interaction. 


\section{Acknowledgements}

Economic support through NOVUS 2013 grants initiative to develop the Widgets Program is acknowledged to Tecnológico de Monterrey.

\section{References}

Allen, K., Seaman, J., \& Garret, R. (2007). Blending in: The extent and promise of blended education in the United States. USA: Sloan Consortium. Retrieved from http://bit.ly/1KETCsp

Algreenand, H. \& Moesby, E. (2001). POL assessment guide for students. Technical report. Aalborg University, Denmark. Retrieved from bit.ly/23WswDx.

Anderson, L. W. \& Krathwohl, D. R. (2001). A taxonomy for learning, teaching and assessing: a revision of Bloom's Taxonomy of educational objectives. New York, USA: Longman.

Ausbel, D. (1963). The psychology of meaningful verbal learning. Oxford, England: Groaning \& Stratton.

Bartolomé, A. (2004). Blended learning, conceptos básicos [, basic concepts]. PixelBit Revista de Medios y Educación, 23, 7-20.

Buzzeto-More, N., \& Sweat-Guy, R. (2006). Hybrid learning defined. Journal of Information Technology Education, 5, 153-156.

Conole, G. (2008). The student perspective: the ever-changing landscape of technology use. ReCALL, 20(2), 124-140.

Delgado, F. (1999). Principia program: experiences of a course with integrated curriculum in collaborative environments and with use of technologies in learning. Proceedings of the II Congress of Scientific Research in the Metropolitan University. Universidad Metropolitana, Caracas, Venezuela.

Delgado, F. (2011). Curricular changes generated by the use of technology in the teaching of numerical methods. Proceedings of the XXXVIII National Conference Engineering. ANFEI, México.

Delgado, F. (2013a). Meaningful Learning of Math and Sciences Using Wolfram Alpha Widgets. In Jan Herrington et al. (Eds.), Proceedings of World Conference on Educational Multimedia, Hypermedia and Telecommunications 2013 (pp. 1794-1799). AACE, Chesapeake, VA, USA. Retrieved from bit.ly/1Q6UaU3.

Delgado, F. (2013b). Physics and Mathematics widgets: internet site. Retrieved from bit.ly/1j4H4vJ.

Delgado, F. \& Santiago, R. (2014). Designing a site to embed and to interact with Wolfram Alpha widgets in Math and Sciences courses. Proceedings of Mobile Learning International Conference 2014 (pp. 266-270). IADIS, Madrid, Spain. Retrieved from bit.ly/1orjpKQ.

Delgado, F. (2014). Actualización docente en tecnologías educativas y aprendizaje móvil: Desarrollo de un programa institucional [Upgrade teaching in educational technologies and mobile learning: Development of an institutional program] . Revista de Formación e Innovación Educativa Universitaria, 7(4), 211-226.

Delgado, F., Santiago, R., \& Quezada, L. (2015). Widget based learning to develop meaningful comprehension in Math and Science courses. Proceedings of INTED 2015, 0750-0758. IATED, Madrid, Spain. 
DeNisco, A. (2014). Different faces of blended learning. District Administration. Retrieved November 11, 2014 from bit.ly/1jAWIVA.

Dougherty, D. (2012). The Maker movement. Innovations, 7(3), 11-14.

DreamBox Learning. (2013). 6 Models of Blended Learning. DreamBox. Retrieved from bit.ly/1j9hdBa.

Edublogs. (2013). The Edublog awards. USA: Edublogs. Retrieved from bit.ly/1ucFQiK.

Educastur. (2012). Use of widgets. Department of Education and Science of the Government of the Principality of Asturias, Asturias, Spain. Retrieved from bit.ly/20KRiHS.

Engelbrecht, J. \& Harding, A. (2005). Teaching Undergraduate mathematics on the internet. Educational Studies in Mathematics, 58(2), 253-276.

Gaer, S. (1998). Less teaching and more learning. Focus on basics. USA: NCSALL. Retrieved from bit.ly/1T6KoGX.

Gkatzidou, V. \& Pearson, E. (2011). A community approach to the development of widgets to support personalised learning for disabled students. Proceedings of ascilite 2011. Retrieved from bit.ly/1RoOH0f.

Gonzalez, H. \& Kuenzi, J. (2012). Science, Technology, Engineering, and Mathematics (STEM) Education: A Primer. Congressional Research Service Report. Retrieved from bit.ly/1PkxAKw.

Guess, A. (2008). A widget onto the future. Inside Higher Education. Retrieved from bit.ly/1WdTil5.

iTEC. (2013). Smart widgets for the iTEC project. Lisbon, Portugal: European Schoolnet.

ITESM. (2007). Project Oriented Learning. ITESM, Monterrey, México.

Johnson, L. Smith, R., Willis, H., Levine, A. and Haywood, K. (2011). The 2011 Horizon Report. Austin, USA: The New Media Consortium.

Kolb, D. (1984). Experiential learning. New York: Prentice Hall.

Laurillard, D. (2002). Rethinking university teaching: a conversational framework for the effective use of learning technologies (2nd ed.). London: Routledge Falmer.

Lothridge, K., Fox, J., \& Fynan, E. (2013). Blended learning: efficient, timely, and cost effective. Journal for Forensic Sciences, 45(4), 407-416.

Pearson, E., Gkatzidou, S., \& Green, S. (2011). Widgets to support the concept of an Adaptable Personal Learning Environment. Proceedings from the IEEE International Conference of Advanced Learning Technologies (ICALT). IEEE, Athens, Georgia, USA. Retrieved from bit.ly/1Q6TOgk.

Polanco, R., Calderon, P., \& Delgado, F. (2001). Effects of a Problem Based Learning program on engineering student' academic achievements, skill development and attitudes in a Mexican university. Proceedings of Annual Meeting of the American Educational Research Association. AERA, USA.

Santiago, R. \& Quezada, L. (2013). Calculus Lab: internet site. Retrieved from bit.ly/1IDuoFD.

Shibley, I. (2014). Putting students in the driver's seat: technology projects to decrease passivity. Faculty Focus. Retrieved from bit.ly/1p5hZ5z.

Staker, H. \& Horn, M. (2012). Classifying K-12 Blended learning. Innosight Institute, Inc., Harvard, USA. Retrieved from bit.ly/liizZmP.

Woessmann, L. (2001). Why students in some countries do better. USA: Education matters. Retrieved from bit.ly/1orgLos.

Young, J. (2008). Professor Uses Web 'Widgets' to Share Course Content. The chronicle of higher education. Retrieved from bit.ly/23WtK1M. 